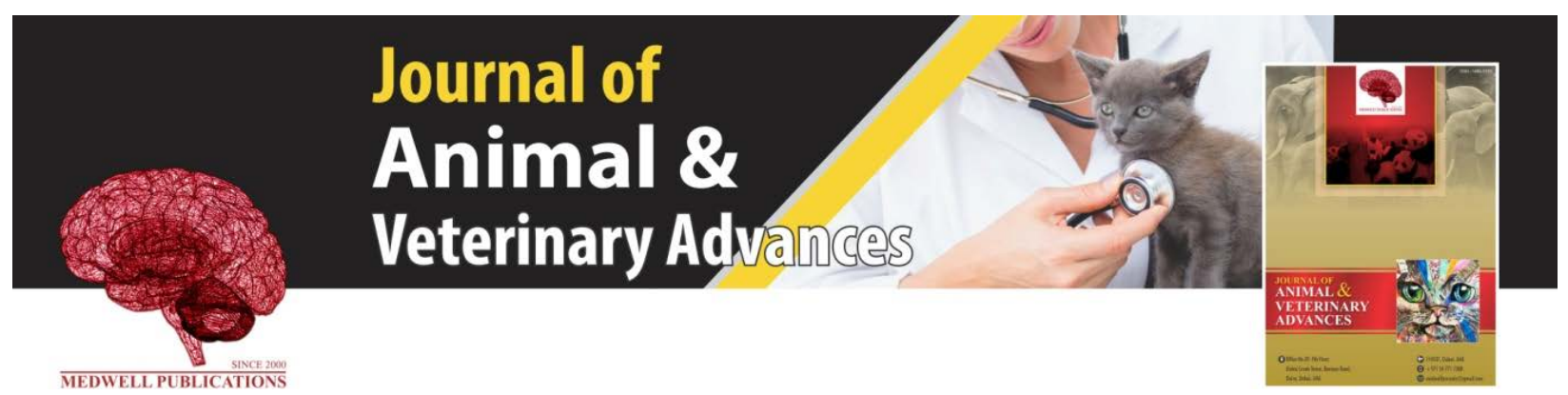

\title{
Determination of Penicillin G in Poultry Meat by High Performance Liquid Chromatography
}

\author{
${ }^{1}$ Abdelhamid Y. Tebbani and ${ }^{2}$ Safinez Boutrid \\ ${ }^{1}$ Department of Veterinary Sciences, Agro-Veterinary Institute, University of Batna 1, Batna, Algeria \\ ${ }^{2}$ Department of Biology of Organisms, Faculty of Natural and Life Sciences, University of Batna 2, Batna, \\ Algeria
}

Key words: Penicillin G, Bacillus subtilis, HPLC-UV, boiling, frying, microwaving

Corresponding Author:

Abdelhamid Y. Tebbani

Department of Veterinary Sciences, Agro-Veterinary Institute, University of Batna 1, Batna, Algeria

Page No.: 284-290

Volume: 18, Issue 9, 2019

ISSN: 1680-5593

Journal of Animal and Veterinary Advances

Copy Right: Medwell Publications
Abstract: Our research was developed to determine penicillin $\mathrm{G}$ residues in edible tissues in broiler chickens and to evaluate the effect of heat treatment on the persistence of these residues. A total of 600 samples from each of liver, kidney and muscle tissues were analyzed by a microbiological method then by a chromatographic analysis which demonstrated that mean concentrations of penicillin $G$ residues were estimated of $39.19 \pm 3.1845$, $56.64 \pm 1.6786$ and $64.46 \pm 2.5065 \mu \mathrm{g} \mathrm{kg}^{-1}$ in the liver, kidneys and muscle, respectively. As we noted that these mean concentrations exceeded the MRLs recommended by the WHO only in the kidney samples. As well, our results demonstrated that boiling positive samples at $100^{\circ} \mathrm{C}$ for $30 \mathrm{~min}$ induces a significant decrease in penicillin $\mathrm{G}$ residues. On the other hand, frying positive samples at $200^{\circ} \mathrm{C}$ for $10 \mathrm{~min}$ as well as microwaving positive samples at a temperature of $20 \pm 2^{\circ} \mathrm{C}$ and at a power of $(800 \mathrm{~W}, 2450 \mathrm{MHz})$ for a minute, induces a very significant reduction of penicillin $\mathrm{G}$ residues. Therefore, cooking methods induce partial destruction of antibiotic residues and they cannot be used as reliable methods to get rid of antibiotic residues in broiler meat and the only way to protect the consumer is to extend the waiting time.

\section{INTRODUCTION}

In front of the growing demand for animal protein from urban populations in North Africa, intensive poultry farming has developed these recent years in several countries. This is the case, for example, of the Algerian poultry industry which has seen a spectacular rise in animal production which has known a spectacular rise in animal production. The Algerian craze for white meats and particularly broilers has become important for nutritional and economic reasons. Thus, the productivity and the profitability of poultry farming has forced the use of antibiotics as growth factors which used at sub-therapeutic doses stimulate animal growth and reduce their mortality and morbidity (Van Immerseel et al., 2003), allowing the consumer to buy at a reasonable cost, high quality meat and eggs (Donoghue, 2003; Aggad et al., 2010). However, the widespread and abusive use of certain antibiotics in poultry farming as well as the non-compliance of waiting times, led to the 
appearance of antibiotic residues in the foodchain and the rapid and worrying emergence of resistant bacterial strains as well as hypersensitivity reactions in the consumer (Zhang et al., 2003; Bada-alambedji et al., 2004). Benzylpenicillin or penicillin $G$ is a beta-lactam antibiotic, widely used in veterinary medicine as a curative and prophylactic treatment and quickly absorbed by the gastrointestinal tract because of its high tissue penetration ability. However, intensive use of penicillins may lead to the to the appearance of their residues in food products of animal origin which would be at the origin of an hypersensitivity to penicillin as well as the development and transfer of antibiotic resistance between animals and humans (Lee et al., 2001; Mitema et al., 2001; McCracken et al., 2005).

Regulations concerning the use of veterinary drugs as the waiting time and tolerance levels have been established to protect the public against possible health risks caused by the presence of drug residues in food of animal origin. However, these regulations are not always respected in countries where the monitoring of drug residues in foods is not performed (Lee et al., 2001; Shitandi and Sternesjo, 2001; Donoghue, 2003). The importance of this health and economic problem and the lack of scientific documentation on the experimental work dealing with this subject in Algeria, show the necessity to do an inventory of fixtures of antibiotic use practices in poultry farming. This research aims to detect and to quantify residues of benzylpenicillin in broiler chicken edible tissues (liver, kidney and muscle) by HPLC-UV as well as to study the thermal effect on the persistence of these residues.

\section{MATERIALS AND METHODS}

Sampling: A total of 600 liver, kidney and muscle tissue samples (200 from each tissue) from broilers that were collected randomly from farms at the wilaya of Ain Touta (Batna, Algeria) from February 2017 to June, 2017. After 45 days of rearing, 200 chickens weighing 2500-3000 g of body weight were slaughtered and the samples collected were preserved in amber bottles, sterile, labeled, containing a Phosphate Buffered Saline solution (PBS) and stored at $-20^{\circ} \mathrm{C}$ until analysis. A minimum weight of $30 \mathrm{~g}$ was respected for each levy.

Reagents and chemicals: Penicillin $G$ potassium salt (purity $\geq 98.0 \%$ ) to be used as a reference analytical standard was obtained from Sigma Aldrich (Ref. 13750). Methanol and acetonitrile were HPLC grades and were obtained from Merck (Darmstadt, Germany). Hydrochloric acid, formic acid and trichloroacetic acid were of analytical grade, obtained from Sigma Aldrich (St. Louis, Missouri, USA).
Extraction and precipitation procedure: The samples to be analyzed were defrosted and comminuted at $3000 \mathrm{rpm}$ for 3 min using a broyeur Ultra Turrax (IKA, Germany). About $5 \mathrm{~g}$ of each ground sample was weighed into a $50 \mathrm{~mL}$ polypropylene centrifuge tube and homogenized with $15 \mathrm{~mL}$ of acetonitrile/water (volume 15:2) for $1 \mathrm{~min}$. Then centrifuged at $4000 \mathrm{rpm}$ at $4^{\circ} \mathrm{C}$ for 5 min using a thermostatic centrifuge (Sigma 3/16 kL, Germany). The supernatants were carefully collected in new clean centrifuge tubes.

Two others extractions were performed and the supernatants were combined. Then vortexed during 3 min with $2 \mathrm{~mL}$ of trichloroacetic acid at $25 \%$ as a deproteinization agent. Then centrifuged at $4000 \mathrm{rpm}$ at $4^{\circ} \mathrm{C}$ for $10 \mathrm{~min}$. The supernatants were then filtered through a cellulose nitrate membrane filter (diameter 25 $\mathrm{mm}$, pore $0.45 \mu \mathrm{m} \times 100$ ) (Ref. 1675181).

Solid phase extraction: About $10 \mathrm{~mL}$ of extract was loaded into the conditioned and equilibrated cartridge SPE Agilent SampliQ OPT 0.04 mL mg ${ }^{-1}$ (Agilent p/n 59823067). The cartridge was washed with $3 \mathrm{~mL}$ of $0.1 \%$ formic acid in water and then with $2 \mathrm{~mL}$ of potassium phosphate buffer pH 8.5. Finally, the sample was eluted with $3 \mathrm{~mL}$ of acetonitrile and filtered through a syringe filter PTFE of $13 \mathrm{~mm}, 45 \mu \mathrm{m}$ (Agilent p/n 5185-5836). The extracts, thus, prepared were resuspended in the mobile phase (1.0 mL) and vortexed (IKA, Germany) for 2 min. Then transferred into amber bottles, ready for introduction into LC-UV system.

Microbiological detection: The pre-selection of meat samples for the presence of antibiotic residues was performed using a microbiological test based on the inhibition of bacterial growth of Bacillus subtilis strain by any antimicrobial residues present in the samples. A pure strain of Bacillus subtilis was obtained from the microbiology service at the CHU of Batna (Algeria). Mueller Hinton Agar ( $\mathrm{pH} \mathrm{6)}$ was prepared according to the manufacturer's instructions and the $\mathrm{pH}$ has been adjusted using $\mathrm{HCl}(0,1 \mathrm{M})$. After autoclaving at a pressure of 15 psi and at a temperature of $121^{\circ} \mathrm{C}$ for $15 \mathrm{~min}$, agar was cooled to $45-55^{\circ} \mathrm{C}$.

Sterile Petri dishes (diameter $90 \mathrm{~mm}$ ) were filled with $15 \mathrm{~mL}$ of medium prepared and inoculated with a pure strain of Bacillus subtilis using a sterile swab then incubated at $30^{\circ} \mathrm{C}$ for $18-24$ h to determine the effect of $\mathrm{pH}$ on bacterial growth. Six wells (diameter $8 \mathrm{~mm}$ ) were perforated in the agar layer and filled with $80 \mu \mathrm{L}$ of the extracts to be analyzed. The wells were at least $30 \mathrm{~mm}$ apart from each other. After a pre-diffusion of $1 \mathrm{~h}$ at room temperature, the dishes were incubated at $30^{\circ} \mathrm{C}$ for $18-24 \mathrm{~h}$. 
After the incubation, the eventual presence of antimicrobial activity in the samples causes the formation of an inhibition zone which diameter was measured using a digital caliper (HDCD01200, INGCO). These diameters were measured with subtraction of the diameter of the perforation well. Samples with an inhibition zone equal or higher than $2 \mathrm{~mm}$ diameter were considered positive.

\section{Chromatographic confirmation}

HPLC system and chromatographic conditions: The samples were analyzed using a high performance liquid chromatography system type HPLC SHIMADZU LC-10A (Japan), equipped with an automatic degasser (DGU-20A5), two high pressure pumps (LC-10 ATvp), a detector UV-vis (SPD-10AVvp), an integrator (SCL-10Avp) and an injector equipped with a $20 \mu \mathrm{L}$ injection loop. The chromatographic separation was realized on a reverse phase analytical column C18 (grafted with silica gel) type SHIMADZU VP-ODS $(250 \times 4.6 \mathrm{~mm}, 5 \mu \mathrm{m})$ with isocratic elution of a methanol solution as a mobile phase. The injection volume was $20 \mu \mathrm{L}$ for all standards and sample extracts with a flow rate of $1 \mathrm{~mL} \mathrm{~min}{ }^{-1}$ and an analysis time of $12 \mathrm{~min}$. The peaks were detected at a wavelength of $220 \mathrm{~nm}$. All samples, solvents and standard solutions must be filtered through a filter membrane type SUPELCO $(0.45 \mu \mathrm{m})$ before use. Data acquisition was controlled by the software Chromatography Workstation Class-VP, Release 6.12, SP1 (SHIMADZU Corporation, Japan).

Standard solution: A stock solution of $0.4 \mathrm{mg} \mathrm{mL}^{-1}$ was prepared by dissolving $8 \mathrm{mg}$ of pure penicillin $\mathrm{G}$ standard in $20 \mathrm{~mL}$ of methanol. The standard solution has been preserved in amber bottles to avoid a possible decomposition and then kept at a temperature of $-20^{\circ} \mathrm{C}$. This solution was stable for a month after which it is replaced by a fresh new solution. A series of standard solutions of; 400, 200, 100, 50, 25 and $10 \mu \mathrm{g} \mathrm{mL}^{-1}$ were prepared to delineate the calibration curve and to evaluate the linearity.

Quantification: The quantitation of penicillin $G$ in the matrices was based on the peak areas of the standards which were used to establish a calibration curve and thus a linearity of the variation of peak area as a function of the variation of penicillin $\mathrm{G}$ concentrations in the different matrices.

Heat treatment of positive samples: Positive confirmed samples were heat treated (boiling, frying and microwave), performed according to the method previously described by Lolo et al. (2006).

Boiling: About $20 \mathrm{~g}$ each of the positive samples were placed in a strainer then immersed in a water bath preheated to $100^{\circ} \mathrm{C}$ that was boiled for $30 \mathrm{~min}$. Following this the samples were removed and let cool.
Frying: About $20 \mathrm{~g}$ of each positive samples were fried in a saucepan containing a suitable amount of preheated cottonseed oil at $200^{\circ} \mathrm{C}$ for $10 \mathrm{~min}$ then removed and let cool.

Microwave: About $10 \mathrm{~g}$ of sample were placed at the geometric center of a turntable microwave at an initial temperature of $20 \pm 2^{\circ} \mathrm{C}$. The sample was cooked at maximum power $(800 \mathrm{~W}, 2450 \mathrm{MHz})$ for a minute. After treatment, all samples were immediately placed in an ice bath and stored at $4^{\circ} \mathrm{C}$ for later analysis within one day. These samples thus, treated were analyzed again by HPLC-UV.

Statistical analysis: Our results are expressed on average \pm SEM. The difference between the results was analyzed by the student test.

\section{RESULTS AND DISCUSSION}

Microbiological analysis: Our results showed that 72, 83 and 51 samples among 200 liver, kidney and muscle samples, respectively were contaminated with antibiotic residues; the percentage of contamination was 36, 41.5 and $25.5 \%$, respectively. Zones of inhibition are presented on average \pm SEM in Table 1. Our results revealed that the average inhibition zones recorded in renal tissue samples were significantly higher than the average inhibition zones observed in liver tissue samples $(4.1037 \pm 0.1557$ vs. $3.5232 \pm 0.326 \mathrm{~mm})$ and muscle samples $\quad(4.1037 \pm 0.1557$ vs. $3.0921 \pm 0.0339 \mathrm{~mm})$ $(\mathrm{p} \leq 0.05)$.

Chromatographic analysis: The relationship between peak area and penicillin $G$ concentration was linear $\left(\mathrm{r}^{2}=0.9998, \mathrm{n}=6\right)$ on a calibration series of $10-400 \mu \mathrm{g} \mathrm{mL}{ }^{-1}$. The curve has been described by the equation $(Y=46.886 x+150.44)$ where « $Y$ » represents the peak area and «X» the concentration. The correlation coefficient was satisfactory and indicated that this procedure was reliable for quantitative detection (Fig. 1). Chromatographic analysis of the results revealed that penicillin $\mathrm{G}$ was detected in 9,17 and 4 liver, kidney and muscle samples, respectively, representing a percentage of $12.5,20.48$ and $7.84 \%$, respectively. With an estimated residual concentration of $39.19 \pm 3.1845,56.64 \pm 1.6786$ and $34.46 \pm 2.5065 \mu \mathrm{g} \mathrm{kg}^{-1}$ in liver, kidney and muscle samples, respectively.

Table 1: Average inhibition zones (mm) antibiotic residues in the samples examined

\begin{tabular}{|c|c|c|c|c|c|}
\hline \multirow{2}{*}{$\begin{array}{l}\text { Samples } \\
\text { examined }\end{array}$} & \multirow{2}{*}{$\begin{array}{c}\text { No. of } \\
\text { samples }\end{array}$} & \multicolumn{2}{|c|}{ Positive samples } & \multicolumn{2}{|c|}{ Inhibition zone (mm) } \\
\hline & & Number & Percentage & Average & SEM \\
\hline Liver & 200 & 72 & 36.0 & 3.5232 & 0.3260 \\
\hline Kidney & 200 & 83 & 41.5 & 4.1037 & 0.1557 \\
\hline Muscle & 200 & 51 & 25.5 & 3.0921 & 0.0339 \\
\hline
\end{tabular}




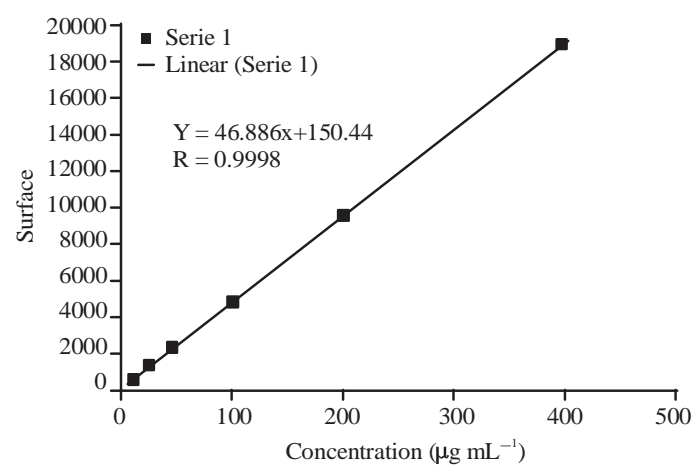

Fig. 1: Calibration curve of penicillin G

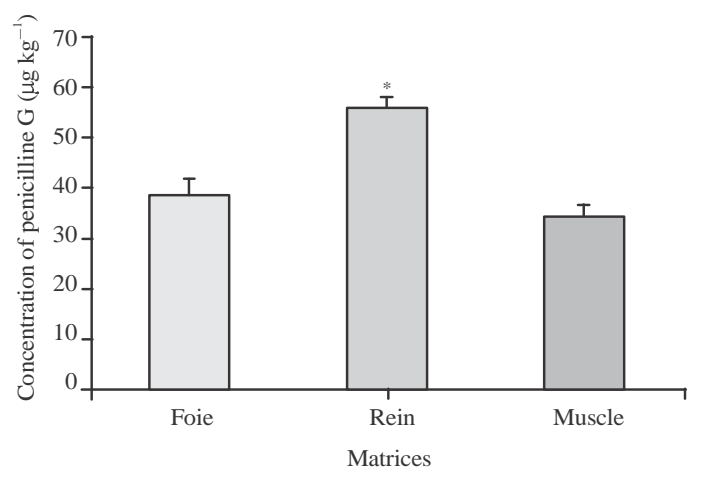

Fig. 2: Residual penicillin G concentration in liver, kidney and muscle in broiler (average \pm SEM in $\left.\mu \mathrm{gg}^{-1}\right)(* \mathrm{p} \leq 0.05)$

Thus, we notice that the average penicillin $G$ concentration in the kidneys exceeds the maximum residue limit (LMR) set by the World Health Organization (WHO) and who is estimated of $50 \mu \mathrm{g} \mathrm{kg}^{-1}$.

On the other hand, the residual concentrations determined in liver and muscles samples are lower than LMR set by WHO which is $50 \mu \mathrm{g} \mathrm{kg}^{-1}$ for these 2 matrices. Following the statistical analysis of the results, we noted that the average penicillin G concentration in the kidneys $\left(56.64 \pm 1.6786 \mu \mathrm{g} \mathrm{kg}^{-1}\right.$ ) was significantly higher than its concentration in the liver $\left(39.19 \pm 3.1845 \mu \mathrm{g} \mathrm{kg}^{-1}\right)$ and muscles $(34.46 \pm 2.5065$ $\left.\mu \mathrm{kg}^{-1}\right)(\mathrm{p} \leq 0.05)$. Penicillin $\mathrm{G}$ concentration in liver samples was higher than muscle concentration. However, the difference was not significant. These results are shown in Fig. 2.

\section{Effect of heat treatment}

Boiling: After boiling at $100^{\circ} \mathrm{C}$ for 30 min of positive samples, results revealed that the penicillin $G$ concentration decreased significantly with a percentage of $47.12,50.28$ and $53.48 \%$ in liver, kidney and muscle samples, respectively. The average of penicillin G

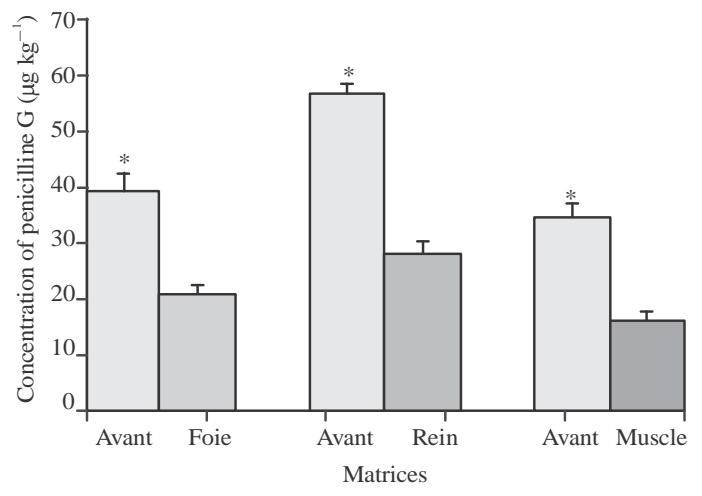

Fig. 3: Effect of boiling at $100^{\circ} \mathrm{C}$ for $30 \mathrm{~min}$ on the concentration of penicillin $\mathrm{G}$ residues (average \pm SEM in $\left.\mu \mathrm{g} \mathrm{kg}^{-1}\right)\left({ }^{*} \mathrm{p}=0.05\right)$

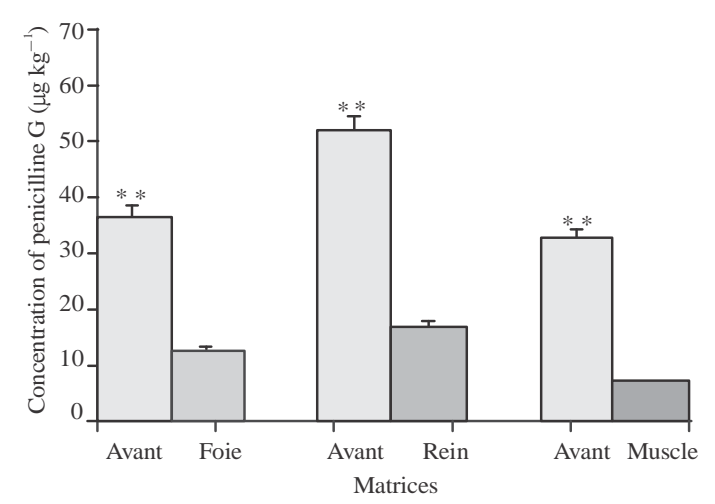

Fig. 4: Effect of frying at $200^{\circ} \mathrm{C}$ for 10 min on the concentration of penicillin $\mathrm{G}$ residues (average \pm SEM in $\left.\mu \mathrm{gg}^{-1}\right)\left({ }^{* *} \mathrm{p} \leq 0.01\right)$

concentration has been reduced of $39.19 \pm 3.1845$ to $20.72 \pm 1.6725 \mu \mathrm{g} \mathrm{kg}^{-1}$ of $56.64 \pm 1.6789$ to $28.16 \pm 1.8694$ $\mu \mathrm{g} \mathrm{kg}^{-1}$ and of $34.46 \pm 2.5065$ to $16.03 \pm 1.5463 \mu \mathrm{g} \mathrm{kg}^{-1}$ for liver, kidney and muscle samples, respectively. Thus, the boiling of the matrices at $100^{\circ} \mathrm{C}$ for 30 min reduced the residual penicillin $\mathrm{G}$ below the MRLs recommended by WHO. These results are shown in Fig. 3.

Frying: After frizzing the samples in cottonseed oil preheated to $200^{\circ} \mathrm{C}$ for $10 \mathrm{~min}$, the results showed that the penicillin $G$ concentration decreased very significantly with a percentage of 68.46, 64.97 and $75.13 \%$ for liver, kidney and muscle samples, respectively. The average concentration of penicillin G residues has been reduced of $39.19 \pm 3.1845$ to $12.36 \pm 1.1875$ of $56.64 \pm 1.6786-19.84 \pm 1.0586$ and of $34.46 \pm 2.5065$ to $8.57 \pm 1.7513 \mu \mathrm{g} \mathrm{kg}^{-1}$ for liver, kidney and muscle samples, respectively. Thus, frying reduced the concentration of penicillin $G$ below the MRLs recommended by WHO. These results are shown in Fig. 4. 


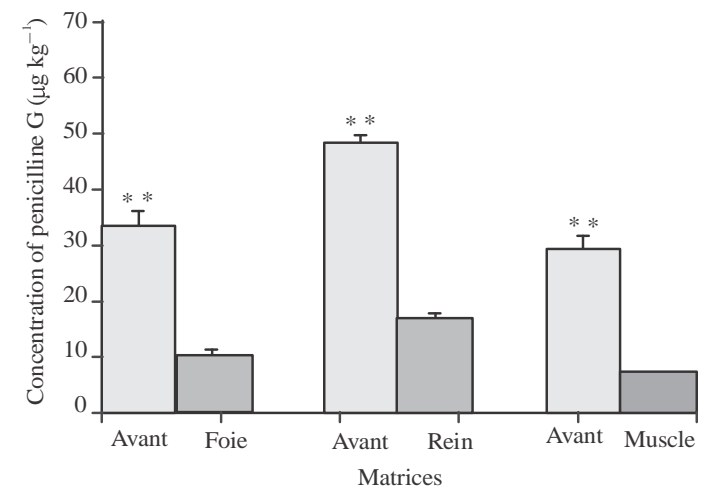

Fig. 5: Effect of microwaving at $20 \pm 2^{\circ} \mathrm{C}$ on the concentration of penicillin $\mathrm{G}$ residues (average \pm $\mathrm{SEM}$ in $\left.\mu \mathrm{g} \mathrm{kg}^{-1}\right)\left({ }^{* *} \mathrm{p} \leq 0.01\right)$

Microwaving: After have been submitted to a temperature of $20 \pm 2^{\circ} \mathrm{C}$ at a power of $(800 \mathrm{~W}, 2450 \mathrm{MHz})$ for a minute. The results of the chromatographic analysis demonstrated that the penicillin $G$ concentration decreased very significantly ( $\mathrm{p} \leq 0.01)$ with a percentage of 70.63, 71.27 and $76.92 \%$ for liver, kidney and muscle samples, respectively. The average concentration of penicillin $G$ residues has been reduced of 39.19 \pm 3.1845 to $11.51 \pm 0.9115$ of $56.64 \pm 1.6786$ to $16.27 \pm 1.2719$ and of $34.46 \pm 2.5065$ to $7.95 \pm 1.1357 \mu \mathrm{g} \mathrm{kg}^{-1}$ for liver, kidney and muscle samples, respectively. Allowing the decrease of penicillin $G$ concentration below the MRLs recommended by WHO. These results are shown in Fig. 5.

The use of antibiotics in livestock animals occupies an important place in production. These drugs that are used to ensure the health status of animals or improve their productions, commonly found in consumer food when the waiting period is not respected. We talk then about the problem of residues of veterinary drugs (Talnan, 2013). The detection of antibiotic residues was realized by a method of microbiological inhibition which consisted of a layer of agar inoculated with a pure strain of Bacillus subtilis at $\mathrm{pH}$ 6. The $\mathrm{pH}$ of the culture medium is an important factor influencing the permeability of bacteria to antibiotics, stability and activity of enzymes that inactivates antibiotics such as penicillinase secreted by Bacillus subtilis bacteria and whose activity can be enhanced at a low $\mathrm{pH}$.

Screening methods are an important part of the integrated approach to monitoring antibiotic residues. However, they must be supplemented by confirmation methods. Samples having revealed antimicrobial activity were subjected to a high performance liquid chromatography confirmatory test with UV detection. Results of microbiological inhibition test and chromatographic analysis revealed that penicillin $G$ residues were detected at a significantly higher concentration in the kidneys, probably due to the fact that this organ represents the main route of elimination of drugs. These results are in agreement with those obtained by Alhendi et al. (2000), Perez et al. (2011) and Wachira et al. (2011) who reported that the maximum average concentration was detected in the kidneys followed by the liver. This would be due to the fact that these organs are involved in the storage, metabolism and elimination of drugs.

The concentration of penicillin $G$ detected in the kidneys was above the MRLs recommended by WHO. This shows that no respect of the waiting period predisposes the consumer to antibiotic residues. These results are consistent with those obtained by Salehzadeh et al. (2006) who indicated that residual levels in chicken meat could pose a potentially serious threat to the health of consumers. In fact, the exposure of the intestinal microflora to antimicrobial residues could contribute to the colonization of the intestine by resistant bacterial strains, compromising antimicrobial therapy in humans by exerting selection pressure on intestinal microflora, thus, promoting the growth of antibiotic-resistant microorganisms.

Basyoni and Brr (2009) stated that the most common causes of the presence of antibiotic residues in food of animal origin are non-compliance with the withdrawal period, overdose of antibiotics and uncontrolled and anarchic use of antibiotics as growth factors or for prophylaxis. In fact, the persistence of antibiotic residues in poultry meat depends on different factors such as dosage, the type and age of the animal, the food, the health status of the animal, mismanagement, the extra-label use of drugs, the waiting time and the route of administration.

On the other hand, mean penicillin G concentration in liver samples was higher than muscle concentration, although this deference was not significant. Similar results were reported by Hussein et al. (2016) when detecting and quantifying oxytetracycline in the liver and muscle tissues of the broiler. They reported that high concentrations of oxytetracycline were recorded in liver samples. This has been attributed to the fact that the liver is responsible of the metabolism and the detoxification of antibiotics by microsomal enzymes. Most foods of animal origin are cooked to increase digestibility, the appetizing attribute and the duration of the conversation. In recent years several studies have been started to evaluate the impact of heat treatment on the persistence of antibiotic residues. The data obtained during this study, demonstrate that boiling the positive samples at a temperature of $100^{\circ} \mathrm{C}$ for 30 min caused a significant decrease in penicillin $\mathrm{G}$ residues. As well as frying at $200^{\circ} \mathrm{C}$ for $10 \mathrm{~min}$ in cottonseed oil and microwaving at a 
temperature of $20 \pm 2^{\circ} \mathrm{C}$ and at a power of $(800 \mathrm{~W}, 2450$ $\mathrm{MHz}$ ) for a minute, caused a very significant decrease in penicillin $\mathrm{G}$ residues.

These results are in agreement with those obtained by Javadi (2011) and Nashwa (2012) who reported that boiling significantly decreased the residual levels of oxytetracycline in turkey meat. El-Kahky and Allam (2005) have revealed that frying has a destructive effect on antibiotic residues. Marouf and Bazalou (2005) concluded that the effect of direct heat from frying oil was more effective than boiling water.

However, our results do not agree with those obtained by Gehan (1991) and Moats (1999) who mentioned that ordinary meat cooking processes could not inactivate even the most sensitive compounds such as penicillin and tetracycline. A subsequently study realized by Gergis-Aida (1998) on the effect of heat treatment such as boiling and frying demonstrated that heat treatment decreased the concentration of antibiotic residues or induced an inactivation of the latter as a function of the degree of temperature and the exposure time.

\section{CONCLUSION}

In conclusion, although, the cooking methods induced a decrease in the residual level of antibiotics they do not represent reliable methods for getting rid of these residues completely because they cause only partial degradation of antibiotic residues. Then, the antibiotics should be used with caution as it becomes imperative and essential to respect the waiting period, so that, the antibacterial drug is metabolized and excreted by the body. This in order to preserve the health of the consumer and to stop the emergence of resistant bacterial strains.

\section{REFERENCES}

Aggad, H., A. Ammar, A. Hammoudi and M. Kihal, 2010. Antimicrobial resistance of Escherichia coli isolated from chickens with colibacillosis. Glob. Vet., 4: 303-306.

Alhendi, A.B., A.A.M. Homeida and E.S. Gaili, 2000. Drug residues in broiler chickens fed with antibiotics in ration. Vet. Arhiv., 70: 199-205.

Bada-alambedji, P.R., E. Cardinal, C. Biagui and A.J. Akakpo, 2004. [Identification of antibacterial substance residues in c hic ken meat consumed in and around Dakar (Senegal) (French)]. Bull. Acad.Vet., 2: 67-70.

Basyoni, S.R. and A.A.H. Brr, 2009. Determination of some antibiotics and sulphonamide residues in meat and liver of rabbit carcasses. Zagazig Vet. J., 37: 178-184.
Donoghue, D.J., 2003. Antibiotic residues in poultry tissues and eggs: Human health concerns?. Poult. Sci., 82: 618-621.

El-Kahky, M.A.A. and T.H. Allam, 2005. Detection of some antibiotic residues in camels meat products. J. Egypt. Vet. Med. Assoc., 65: 203-209.

Gehan, R.M., 1991. Studies on the withdrawal time of some antibiotics from broilers and rabbits. MSc Thesis, Zagazig University, Zagazig, Egypt.

Gergis-Aida, F., 1998. Tetracycline residues in broiler carcasses. Benisuef Vet. Med. Res., 3: 159-172.

Hussein, M.A., M.M. Ahmed and A.M. Morshedy, 2016. Effect of cooking methods on some antibiotic residues in chicken meat. Jpn. J. Vet. Res., 64: S225-S231.

Javadi, A., 2011. Effect of roasting, boiling and microwaving cooking method on doxycline residues in edible tissues of poultry by microbial method. Afr. J. Pharm. Pharmacol., 5: 1034-1037.

Lee, M.H., H.J. Lee and P.D. Ryu, 2001. Public health risks: Chemical and antibiotic residuesreview. Asian Australas. J. Anim. Sci., 14: 402-413.

Lolo, M., A.S. Pedreir, J.M. Miranda, B.I. Vazquez, C.M. Franco, A.A. Ceped and C. Fente, 2006. Effect of cooking on enrofloxacin residues in chicken tissue. Food Addit. Contam., 23: 988-993.

Marouf, H.A. and M.S. Bazalou, 2005. Detection of antibiotic residues in meat sold in Damietta governorate. Proceedings of the 4th International Conference on Scientfic, April 5-6, 2005, Mansoura University, Mansoura, Egypt, pp: 509-519.

McCracken, R.J., J.A. Van Rhijn and D.G. Kennedy, 2005. Transfer of nitrofuran residues from parent broiler breeder chickens to broiler progeny. Br. Poult. Sci., 46: 287-292.

Mitema, E.S., G.M. Kikuvi, H.C. Wegener and K. Stohr, 2001. An assessment of antimicrobial consumption in food producing animals in Kenya. J. Vet. Pharmacol. Ther., 24: 385-390.

Moats, W.A., 1999. The effect of Processing on Veterinary Residues in Foods. In: Impact of Processing on Food Safety, Jackson, L.S., M.G. Knize and J.N. Morgan (Eds.). Springer, Berlin, Germany, ISBN: 9780306460517, pp: 233. 
Nashwa, M.Z., 2012. Seasonal variation of antibiotic residues in some slaughtered animal. Ph.D Thesis, Department of Food Control, Zagazig University, Zagazig, Egypt.

Perez, D.S., A.L. Soraci, S.N. Dieguez and M.O. Tapia, 2011. Determination and withdrawal time of fosfomycin in chicken muscle, liver and kidney. Int. J. Poult. Sci., 10: 644-655.

Salehzadeh, F., R. Madani, A. Salehzadeh, N. Rokni and F. Golchinefar, 2006. Oxytetracycline residue in chicken tissues from Tehran slaughterhouses in Iran. Pak. J. Nutr., 5: 377-381.

Shitandi, A. and A. Sternesjo, 2001. Detection of inhibitory substances in Kenyan milk. J. Food Saf., 21: 205-214.

Talnan, A., 2013. Control of veterinary drug residues in food of animal origin. Ph.D Thesis, University of Dakar yDakary, yRegion.
Van Immerseel, F., L. Meulemans, J. De Buck, F. Pasmans and F. Haesebrouck et al., 2003. Early Protection Against Salmonella Enteritidis after Vaccination with a Live Strain is Abolished by Depletion of the Heterophilic Granulocytes. In: Early Protection Against Salmonella Infection in Chickens by Modification of the Initial HostPathogen Interactions, Van Immerseel, F. (Ed.). Ghent University, Ghent, Belgium, pp: 123-143.

Wachira, W.M., A. Shitandi and R. Ngure, 2011. Determination of the limit of detection of penicillin $G$ residues in poultry meat using a low cost microbiological method. Int. Food Res. J., 18: 1203-1208.

Zhang, Q., J. Lin and S. Pereira, 2003. Fluoroquinolone-resistant Campylobacter in animal reservoirs: Dynamics of development resistance mechanisms and ecological fitness. Anim. Health Res. Rev., 4: 63-72. 